\title{
Adsorption/oxidation of sulfur-containing gases on nitrogen-doped activated carbon
}

\author{
Qiang LIU ${ }^{1}$, Ming KE ${ }^{1}$, Pei YU ${ }^{1}$, Hai Qiang $\mathrm{HU}^{1}$, Xi Ming YAN ${ }^{1}$ \\ ${ }^{1}$ College of Science, China University of Petroleum-Beijing, 102249 Beijing, China
}

\begin{abstract}
Coconut shell-based activated carbon (CAC) was used for the removal of methyl mercaptan (MM). CAC was modified by urea impregnation and calcined at $450^{\circ} \mathrm{C}$ and $950^{\circ} \mathrm{C}$. The desulfurization activity was determined in a fixed bed reactor under room temperature. The results showed that the methyl mercaptan adsorption/oxidation capacity of modified carbon caicined at $950^{\circ} \mathrm{C}$ is more than 3 times the capacity of original samples. On the other hand, the modified carbon caicined at $950^{\circ} \mathrm{C}$ also has a high capacity for the simultaneous adsorption/oxidation of methyl mercaptan and hydrogen sulfide. The introduce of basic nitrogen groups siginificantly increases the desulfurization since it can facilitate the electron transfer process between sulfur and oxygen. The structure and chemical properties are characterized using Boehm titration, $\mathrm{N}_{2}$ adsorption-desorption method, thermal analysis and elemental analysis. The results showed that the major oxidation products were dimethyl disulfide and methanesulfonic acid which adsorbed in the activated carbon.
\end{abstract}

\section{Introduction}

Methyl mercaptan $\left(\mathrm{CH}_{3} \mathrm{SH}\right)$ and hydrogen sulfide $\left(\mathrm{H}_{2} \mathrm{~S}\right)$, which exit in the chemical gas from crude oil, petrolum, coal, natural gas and many other industrial gases, are the major compositions of sulfur compounds [1-3]. Release of the sulfur-containing gases into the atmosphere will cause environmental problems since they can be oxidated into sulfate and sulfonic species. However, a small amount of methyl mercaptan and hydrogen sulfide can poison the catalyst in many industrial processes such as the synthesis of ammonia and Fischer-Tropsch. In few decades, there are many efforts for the deep removal of hydrogen sulfide and methyl mercaptan. The main processes for the removal of methyl mercaptan and hydrogen sulfide include adsorption, biological degradation, incineration and adsorption/oxidation, et al [4-5]. Among the above technologies, adsorption/oxidation is recognized as a promising method due to the high efficiency, low investment and mild operating conditions.

Activated carbons are widely used in the gas purification process due to the well-devoloped porous structure, large removal capacity and easy regeneration property. The removal capacity for methyl mercaptan and hydrogen sulfide also depends on the surface chemistry, such as nitrogen groups and metal oxides. The purpose of the paper is to study the introduction of nitrogen through the impregnation and calcination method and its effect on the adsorption/oxidation of methyl mercaptan in the existence of hydrogen sulfide. In order to study the reaction mechnisam, the original and modified carbons were determined by Boehm titration, $\mathrm{N}_{2}$ adsorptiondesorption method, thermal analysis and elemental analysis.

\section{Experimental}

\subsection{Materials}

The original coconut shell-based activated carbon was obtained from Beijing Kecheng Guanghua New Technology Co, LTD. The size of the original activated carbon was 40-60 mesh. The activated carbon was washed with distilled water and dried at $115^{\circ} \mathrm{C}$ for $12 \mathrm{~h}$. This coconut shell-based activated carbon was designed as $\mathrm{CAC}$.

Firstly, CAC was oxidated using 30 wt. $\% \mathrm{HNO}_{3}$ solution at $60^{\circ} \mathrm{C}$ and stirred for $2 \mathrm{~h}$. Then, the oxidative activated carbon was washed using distilled water until neutral $\mathrm{pH}$ and dried at $115^{\circ} \mathrm{C}$ for $12 \mathrm{~h}$. Secondly, $3 \mathrm{~g}$ oxidated sample was mixed with a saturated urea solution and stirred for $24 \mathrm{~h}$ at $25^{\circ} \mathrm{C}$. Then the mixture was heated to accelerate the evaporation process and the carbon was dried at $115^{\circ} \mathrm{C}$. Thirdly, the impregnation activated carbon was heated in nitrogen from room temperature to $450^{\circ} \mathrm{C}$ or $950^{\circ} \mathrm{C}$ at $10^{\circ} \mathrm{C} / \mathrm{min}$ and kept at this temperature for half an hour. Then boiling water was used to wash the carbon. At last, the samples were heated at $115^{\circ} \mathrm{C}$ for $12 \mathrm{~h}$. The samples were designated as $\mathrm{CAC}-450\left(450^{\circ} \mathrm{C}\right)$ and CAC- $950\left(950^{\circ} \mathrm{C}\right)$. A supernumerary letter $\mathrm{E}$ was added to represent the exhausted samples after the desulfurization test.

\footnotetext{
${ }^{\text {a }}$ Corresponding author: keming@cup.edu.cn
} 


\subsection{Methods}

\subsubsection{Breakthrough capacity}

Dynamic tests were performed to evaluate the removal capacity of $\mathrm{CH}_{3} \mathrm{SH}$ under atmospheric pressure. Before the test, moist air was used moisten the adsorbents and the time was $1 \mathrm{~h}$. Then the moist gas mixture was used to test the desulfurization activity.The inlet concentration of $\mathrm{CH}_{3} \mathrm{SH}$ was $0.3 \%$ in volume. The reactor condition was as follows: reaction temperature $25^{\circ} \mathrm{C}$, relative humidity $80 \%\left(25^{\circ} \mathrm{C}\right)$, overall gas hourly space velocity (GHSV) $5000 \mathrm{~h}^{-1}$. The test was stopped when the outlet concentration of $\mathrm{CH}_{3} \mathrm{SH}$ was $50 \mathrm{ppm}$. To study the stimultaneous removal capacity of $\mathrm{CH}_{3} \mathrm{SH}$ and $\mathrm{H}_{2} \mathrm{~S}$, the mixture air containing $0.3 \% \mathrm{CH}_{3} \mathrm{SH}$ and $0.03 \% \mathrm{H}_{2} \mathrm{~S}$ was also used. The concentrations of $\mathrm{CH}_{3} \mathrm{SH}$ and $\mathrm{H}_{2} \mathrm{~S}$ were analysed using GC-6890 gas chromatography with a PFPD detector. The adsorption capacity was calculated by integration of the area above the breakthrough curves.

\subsection{2 $\mathrm{pH}$ of carbon surface}

$0.4 \mathrm{~g}$ carbon power was mixed with $20 \mathrm{ml}$ water and the mixture was kept at room temperature for $12 \mathrm{~h}$. Then the $\mathrm{pH}$ of the suspension liquid was denoted as $\mathrm{pH}$ of the carbon surface. For the exhausted samples, the $\mathrm{pH}$ was desigated as pHE.

\subsubsection{Sorption of nitrogen}

Nitrogen isotherms were measured at $77 \mathrm{~K}$ using a NOVA2000e (Quantachrome instruments) surface area analyzer. The samples were heated at $120^{\circ} \mathrm{C}$ and outgassed at the temperature for $12 \mathrm{~h}$. The specific surface area was determined using Braunuer-Emmett-Teller measurements (BET) method. Nonlocal Density Functional Theory (NLDFT) was used to calculate the micropore volume $\left(\mathrm{V}_{\text {mic }}\right)$ and pore size distribution. The total pore volume $\left(\mathrm{V}_{t}\right)$ was obtained by the amount of $\mathrm{N}_{2}$ adsorped when $\mathrm{p} / \mathrm{p}_{0}=0.99$.

\subsubsection{Boehm titration}

The method of Boehm was used to determine the acidic and basic surface groups. The numbers of acidic sites and basic sites were calculated according to the corresponding amounts of $\mathrm{NaOH}$ and $\mathrm{HCl}$.

\subsubsection{Thermal analysis}

Thermal analysis was performed using a TGA/DSC1 (Mettler Toledo) instruments thermal analyzer. The setting were as follows : heating rate, $10^{\circ} \mathrm{C} / \mathrm{min}$, argon atmosphere with $50 \mathrm{ml} / \mathrm{min}$.

\subsubsection{Elemental analysis}

The content of carbon, hydrogen and nitrogen was determined using Vario EL elementary analyzer.

\section{Results and discussion}

Elemental analysis results are shown in Table 1. The nitrogen content was siginificantly increased after modifying with urea and calcining at certain temperature. Since the calcination temperature is important for the dissociation of nitogen-containing species, the nitrogen content in CAC-450 is highest due to the incomplete decomposition of nitrogen-containing compounds. When the calcination temperature reaches at $950^{\circ} \mathrm{C}$, many nitrogen-containing groups decompose thus resulting in a decrease in the nitrogen content. After the calcination at $950^{\circ} \mathrm{C}$, the majority of nitrogen incorporated into the sample matrix. The nitrogen mainly existed in the form of pyridine-like or quaternary configuration.

The surface chemistry of the activated carbon was studied and the results were shown in Table 2. The $\mathrm{pH}$ of the sample surface increased after introduction of nitrogen. The Boehm titration results were also shown in Table2. Since the nitrogen-containing species and oxygen-based species can have similar $\mathrm{pKa}$, so the results include only acidic and basic groups. The amount of basic groups increased after modification with urea. The results were in aggrement with the changes in the surface $\mathrm{pH}$.

Table1. Elemental analysis of the carbon samples

\begin{tabular}{cccc}
\hline Sample & C & H & N \\
\hline CAC & 81.15 & 0.75 & 0.13 \\
CAC-450 & 87.38 & 1.38 & 2.25 \\
CAC-950 & 90.92 & 0.91 & 1.16 \\
\hline
\end{tabular}

Table2. pH and surface chemistry from Boehm titration (number of groups in $\mathrm{mmol} / \mathrm{g}$ )

\begin{tabular}{ccccc}
\hline Sample & $\mathrm{pH}$ & Acidic & Basic & Basic/Total \\
\hline CAC & 7.51 & 0.35 & 0.43 & 0.55 \\
CAC-450 & 8.47 & 0.39 & 0.57 & 0.59 \\
CAC-950 & 9.43 & 0.31 & 0.65 & 0.68 \\
\hline
\end{tabular}

The surface area and pore structure are important in the removal process. $\mathrm{N}_{2}$ adsorption isotherms and micropore size distribution curves are shown in Figure1 and Figure2. The textural parameters were calculated based on the nitrogen isotherms and the results were shown in Table3. The pore $<2 \mathrm{~nm}$ is called micropore based on the IUPAC classification. For the different samples, the adsorption isotherms were all similar and the results show that they were micropore materials. For the sample treated at $450^{\circ} \mathrm{C}$, the surface area and pore volume decreased compared with the originanl sample. Otherwise, for the sample treated at $950^{\circ} \mathrm{C}$, the surface area and pore volume slightly increased. For the exhaustion samples, the decrease in the total pore volume might be due to the reaction products adsorbed on the carbon surface. For the 
exhaustion sample CAC-950E, the relative large decrease in the pore volume, especially the micropore volume, suggested that the existence of more strongly adsorbed productions after the breakthrough test. This will be discussed in the later part of the paper.

Table3. Structural parameters of carbon samples from sorption of nitrogen

\begin{tabular}{ccccc}
\hline Sample & $\begin{array}{c}\mathrm{S}_{\mathrm{BET}}\left(\mathrm{m}^{2}\right. \\
/ \mathrm{g})\end{array}$ & $\mathrm{V}_{\mathrm{mic}}\left(\mathrm{cm}^{3} / \mathrm{g}\right)$ & $\mathrm{V}_{\mathrm{t}}\left(\mathrm{cm}^{3} / \mathrm{g}\right)$ & $\mathrm{V}_{\mathrm{mic}} / \mathrm{V}_{\mathrm{t}}$ \\
\hline CAC & 772 & 0.279 & 0.390 & 0.72 \\
CAC-450 & 738 & 0.258 & 0.419 & 0.62 \\
CAC-950 & 783 & 0.279 & 0.421 & 0.66 \\
CAC-450E & 717 & 0.256 & 0.415 & 0.62 \\
CAC-950E & 695 & 0.242 & 0.407 & 0.59 \\
\hline
\end{tabular}

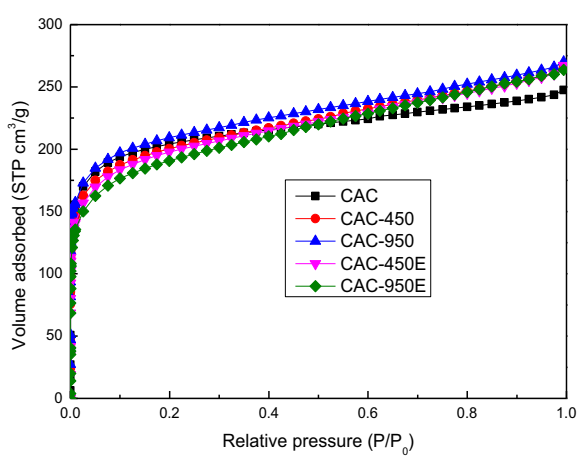

Figure1.Nitrogen adsorption isotherms of the initial and exhausted samples

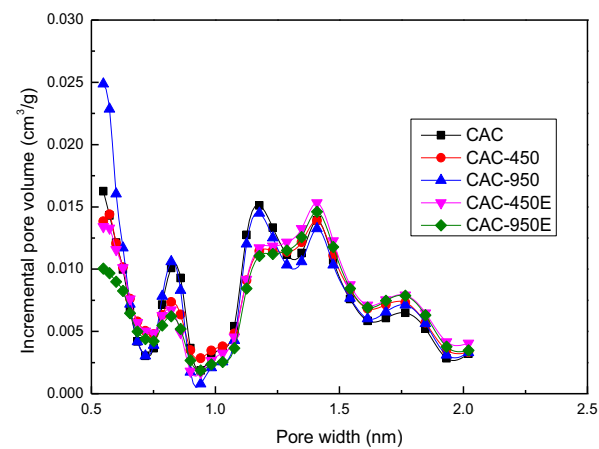

Figure2. Micropore size distributions of the initial and exhausted samples

The breakthrough results were shown in Figure 3 and Table4. After modification with urea, the $\mathrm{CH}_{3} \mathrm{SH}$ capacity increased. For the carbon treated at $950^{\circ} \mathrm{C}$, the $\mathrm{CH}_{3} \mathrm{SH}$ capacity exceeds more than 3 times of the CAC sample. The reason maybe that the nitrogen incorporated into the carbon martix can catalysis the oxidation reaction through improving the electron transfer rates from sulfur to oxygen. The intersting behavior is that the sample treated at $950^{\circ} \mathrm{C}$ shows good simultaneous adsorption/oxidation of methyl mercaptan and hydrogen sulfide. Since the content of hydrogen sulfide is much lower than methyl mercaptan, hydrogen sulfide can not be detected in the outlet gas. The results show that the modified sample can be used for the simultaneous adsorption/oxidation of methyl mercaptan and hydrogen sulfide. For all the samples, $\mathrm{pH}$ of the carbon surface decreased after the breakthrough test. For the modified samples, the large decrease in the $\mathrm{pH}$ indicated that some acid species were part of the oxidation products. The results can be explained in the later DTG results.

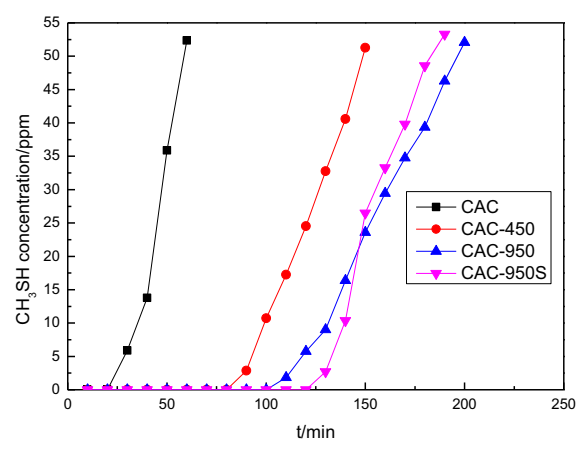

Figure 3. $\mathrm{CH}_{3} \mathrm{SH}$ breakthrough curves

Table4. pH of exhausted samples, their $\mathrm{CH}_{3} \mathrm{SH}$ breakthrough capacity and the amount of water preadsorbed on the carbon surface

\begin{tabular}{cccc}
\hline Sample & $\begin{array}{c}\text { Water } \\
\text { preadsorbed } \\
(\mathrm{mg} / \mathrm{g})\end{array}$ & $\begin{array}{c}\mathrm{CH}_{3} \mathrm{SH} \\
\text { breakthrough } \\
\text { capacity }(\mathrm{mg} / \mathrm{g})\end{array}$ & $\mathrm{pHE}$ \\
\hline CACE & 81.2 & 71.8 & 6.25 \\
CAC-450E & 89.5 & 169.5 & 7.38 \\
CAC-950E & 78.6 & 232.6 & 4.85 \\
CAC-950SE & 78.6 & 230.2 & 4.71 \\
\hline
\end{tabular}

Thermal analysis (TA) can be used to evaluate the adsorbed species on the carbon surface. The differential thermogravimetry (DTG) results are shown in Fig4. For all the samples, there are two main peaks. The first peak centered at about $80{ }^{\circ} \mathrm{C}$ which means desorption of water. According to the results reported by many researchers, the second peak which centered beween $80^{\circ} \mathrm{C}$ and $300^{\circ} \mathrm{C}$ may represent desorption of dimethyl disulfide [6]. An interseting behavior was found for the sample treated at $950^{\circ} \mathrm{C}$. There is another peak centered between $300^{\circ} \mathrm{C}$ to $350^{\circ} \mathrm{C}$. According to the previous research, the peak centered between $300^{\circ} \mathrm{C}$ to $350^{\circ} \mathrm{C}$ may represent the strongly adsorbed species [7]. Based on the $\mathrm{pH}$ decrease and the literature, the peak centered between $300^{\circ} \mathrm{C}$ to $350^{\circ} \mathrm{C}$ may represent strongly adsorbed sulfonic acid species. The DTG results also were in accordance with the breakthrough tests. 


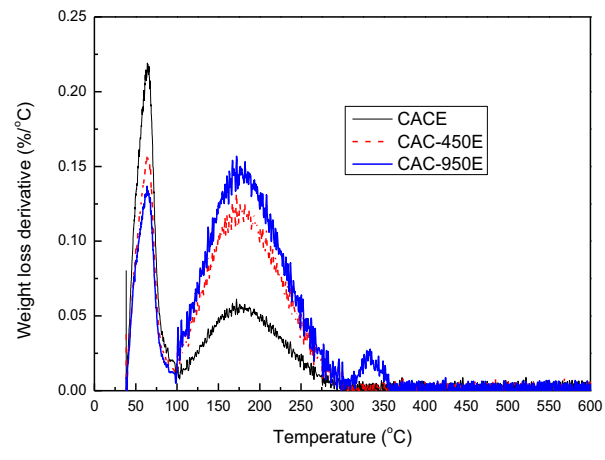

Figure4. DTG curves for the exhausted samples

\section{Conclusions}

The coconut shell-based activated carbon can be used as good materies for the adsorption/oxidation of sulfurcontaining gases in many industrial processes. The sample modified by urea and calcined at $950^{\circ} \mathrm{C}$ indicates high adsorption/oxidation capacity for methyl mercaptan and the adsorption capacity is more than 3 times the capacity of original sample. On the other hand, the modified sample also shows high efficiency for the simultaneous adsorption/oxidation of methyl mercaptan and hydrogen sulfide. The basic nitrogen groups are highly dispersed on the carbon surface and act as catalytic sites for the oxidation of sulfur-containing gases. Dimethyl disulfide and sulfonic acid species are the major oxidation productions.

\section{References}

1. A. Tangerman, E.G. Winkel. Phosphorus Sulfur 188(2013), 396-402.

2. A. Bagreev, J.A. Menendez, I. Dukhno, Y. Tarasenko, T.J. Bandosz, Carbon, 43(2005), 208-210.

3. S. Bashkova, A. Bagreev, T.J. Bandosz, Langmuir, 19 (2003), 6115-6121.

4. C. Cammarano, E. Huguet, R. Cadours, C. Leroi, Appl. Catal. B Environ, 156 (2014),128-133.

5. M.G. Conti-Ramsden, K. Nkrumah-Amoako, N.W. Brown, Adsorption 19(2013), 989-996.

6. C.A. Cellier, V. Vromman, V. Ruaux, E.M. Gaigneaux, J. Phys. Chem. B, 108(2004), 998910001.

7. T. Zeng, W.A. Arnold, B.M. Toner, Environ. Sci. Technol, 47 (2013), 1287-1296. 